\title{
Differential sensitization of cancer cells to doxorubicin by DHA: a role for lipoperoxidation
}

\author{
Karine MAHEO ${ }^{1}$, Sophie VIBet ${ }^{1}$, Jean Paul Steghens ${ }^{2}$, Caroline DARTigeAs ${ }^{1}$, Magali \\ LEHMAN $^{1}$, Philippe BOUGNOUX ${ }^{1}$ and Jacques GORE ${ }^{1}$
}

${ }^{1}$ INSERM E 0211 "Nutrition, Croissance et Cancer"; IFR 135 "Imagerie Fonctionnelle"; Université François-Rabelais, Tours, France ;

${ }^{2}$ Hôpital Edouard Herriot, Lyon, France.

Acknowledgments: We are grateful to Dr. K. CowAN (National Cancer Institute, Bethesda) for the gift of resistant cell line MCF-7dox used in this study. We thank Lysiane BoULAY for excellent technical assistance. This work was supported in part by grants from Ligue Nationale contre le Cancer (Comités d'Indre et Loire, Loir et Cher, Indre), by Institut National de la Santé et de la Recherche Médicale (INSERM: Action Thématique Concertée "Nutrition"), by Conseil Régional (Région Centre) and by Cancéropôle Grand-Ouest. Sophie VIBET was the recipient of a fellowship from the Ministère de l'Enseignement Supérieur et de la Recherche. Caroline DARTIGEAS was the recipient of a fellowship from the Fondation pour la Recherche Médicale.

Correspondence to : Pr. J. GoRÉ, Université François-Rabelais INSERM E 0211 "Nutrition, Croissance et Cancer", Faculté de Médecine, 10 boulevard Tonnellé, F-37032 Tours Cedex, France. fax : +33-0-247-36-62-26 e-mail : jacques.gore@univ-tours.fr 


\title{
Differential sensitization of cancer cells to doxorubicin by DHA: a
}

\author{
role for lipoperoxidation
}

\begin{abstract}
Polyunsaturated fatty acids have been reported to enhance the cytotoxic activity of several anticancer drugs. In the present study, we observed that doxorubicin chemosensitization of breast cancer cell lines by docosahexaenoic acid (DHA, a long chain omega-3 polyunsaturated fatty acid) was cell-line selective, affecting MDA-MB-231 and MCF-7dox (a doxorubicin resistant cell line) but not the parental MCF-7 cell line. DHA supplementation led to an increase in membrane phospholipid DHA level, but did not induce changes in intracellular ${ }^{14} \mathrm{C}$-doxorubicin accumulation. In MDA-MB-231, doxorubicin efficacy enhancement by DHA was linked to an increase in malondialdehyde level, a final product of lipid peroxidation. DHA elicited by itself a 3.7-fold malondialdehyde level increase, additive to that induced by doxorubicin. Addition of doxorubicin to DHA further increased glutathione level, indicative of the generation of an oxidative stress. In contrast to MDA-MB-231, doxorubicin did not increase malondialdehyde level in MCF-7, although DHA induced lipid peroxidation. Therefore in MCF-7, lipid peroxidation induced by DHA itself was not sufficient to trigger an oxidative stress and to subsequently increase sensitivity to doxorubicin. These data indicate that the differential effect of DHA among cells on drug toxicity results from a differential oxidative response to doxorubicin. Chemosensitization through fatty acids appears as a new promising adjuvant therapeutic paradigm, since omega-3 fatty acids are physiological molecules found in food and are non-toxic in vivo.
\end{abstract}

Key words: Breast cancer ; Fatty acids omega-3 ; Anthracycline ; Drug accumulation, Oxidative stress. 


\section{INTRODUCTION}

Several epidemiological studies have indicated that populations consuming high amounts of omega-3 (n-3) fatty acids, display a lower breast cancer risk [1,2]. This effect seems to be related to specific n-3 polyunsaturated fatty acids and/or to the ratio of n- 6 to n-3 fatty acids [3-6]. Long-chain n-3 fatty acids found in fatty cold-water fish, particularly eicosapentaenoic acid (EPA, 20:5n-3) and docosahexaenoic acid (DHA, 22:6n-3) have been shown to inhibit the growth of human breast cells both in culture and in xenografts $[7,8]$ and to increase the efficacy of anticancer drugs $[9,10]$.

Several mechanisms have been proposed to account for the activity of n-3 polyunsaturated fatty acids (n-3 PUFAs) against cancer cells, including: alteration in gene expression [11, 12], modulation of cellular proliferation, apoptosis and differentiation [13], increase in drug transport across cell membrane [14, 15], generation of free oxygen radicals and lipid peroxidation $[16,17]$. These biological mechanisms which could explain n-3 fatty acids-mediated inhibition of mammary carcinogenesis are not independent. For example, incorporation of n-3 polyunsaturated fatty acids into cell membrane phospholipids can alter membrane fluidity (and increase intracellular drug accumulation), modulate cell signalling [18] and enhance the production of free oxygen radicals [19] and lipid peroxidation [20].

Anthracyclines are among the most active anticancer agents, widely used in treatment of solid tumours and leukaemia. The cytotoxic action of doxorubicin has been mainly related to inhibition of topoisomerase II and to the production of oxygen-reactive species [21, 22]. Among polyunsaturated fatty acids, DHA, with its 6 double-bonds, is very prone to oxidation. The increased membrane unsaturation index consequently would provide more abundant targets for oxygen-reactive species generated by doxorubicin metabolism. Products of lipid peroxidation such as hydroperoxides and aldehydes have been implicated in cytotoxic process 
and increase the drug efficacy. Thus, conditions favouring an increased lipid peroxidation in response to doxorubicin would lead to a higher activity of the drug. Among PUFAs studied, DHA was the most potent to enhance the cytotoxic effect of doxorubicin [9]. In vivo and in vitro studies on the influence of DHA supplementation have reported higher peroxidation and oxidative stress, as demonstrated by an increase of thiobarbituric acid-reactive substances, conjugated dienes or malondialdehydes and a decrease of antioxidant vitamins [23-26]. Protection against oxidative damages is normally ensured by non-enzymatic (especially vitamins provided by diet) and enzymatic (catalases, superoxide dismutases, and glutathione peroxidases) defences. Changes in the activity of these antioxidant enzymes have also been described during PUFA supplementation [27, 28].

Chemotherapy has improved during the last decades, largely due to the introduction of effective drug combinations and treatment schemes. However resistance is frequently observed in tumours undergoing primary therapy or, more frequently, is a result of treatment with various antitumour drugs. This Multidrug resistance, the so-called phenotype MDR, remains a major obstacle for successful chemotherapeutic cure [29]. Among drug resistance mechanisms, the most common are $: i$ ) an increase in drug efflux, associated with over-expression of the mdr-1 gene product, a Mr 170000 plasma membrane glycoprotein (P-gp) that functions as an energy (ATP)-dependent efflux pump for cytotoxic drugs and $i$ ) an abnormal redox status developed secondary after drug exposure, in which glutathione and antioxidant enzyme activities are elevated and protect the cell against free radicals aggression [30]. Attention has been focused recently on the study of the agents of MDR reversing agents. Although hundreds of compounds have been found in vitro to be able to modulate the MDR phenotype, their clinical application was limited owing to high toxicity in vivo such as cardiotoxicity, nephrotoxicity or immunosuppression [29]. 
To determine to what extent an oxidative stress could account for the sensitization of cancer cells to doxorubicin by DHA, we have used three cell lines : a doxorubicin-resistant one (MCF-7dox) and two sensitive lines (MCF-7, MDA-MB-231), and took advantage of their differing properties. We found that DHA was able to enhance doxorubicin cytotoxicity in MDA-MB-231 or in MCF-7dox cell lines, but not in parental MCF-7 cell line. In order to understand the differential effects of DHA on these three cell lines, fatty acid composition of membrane phospholipids, and intracellular accumulation of doxorubicin were examined. The cellular oxidative status was also evaluated through the measure of two parameters of oxidative stress, malondialdehyde level (a final product of lipid peroxidation), glutathione levels, cofactor for major antioxidant enzymes which modulates cell response to redox changes and vitamin E level. 


\section{MATERIALS AND METHODS}

\section{Drugs and chemicals}

Unless otherwise stated, all chemicals were purchased from Sigma (Sigma-Aldrich Chimie, France). Doxorubicin (chlorhydrate de doxorubicine Teva ${ }^{\circledR}, 10 \mathrm{mg} / 5 \mathrm{ml}$ ) was purchased from Teva Pharma S.A. (France) and $\left[14-{ }^{14} \mathrm{C}\right]$-Doxorubicin hydrochloride (2 GBq / mmol) was purchased from Amersham Pharmacia Biotech (France). Stock solutions of doxorubicin $(1 \mathrm{mM})$ were stored at $-80^{\circ} \mathrm{C}$ and dilutions of doxorubicin were freshly prepared in Hanks' medium (Hanks' balanced salts without sodium bicarbonate and phenol red) buffered with $10 \mathrm{mM}$ Hepes $\left(\mathrm{pH} 7.2\right.$ at $\left.37^{\circ} \mathrm{C}\right)$ or in appropriate media.

$\left[14-{ }^{14} \mathrm{C}\right]$-Doxorubicin hydrochloride was used at $5 \mu \mathrm{M}$ (final concentration with isotopic dilution $\approx 1 / 11)$. Oleic acid (OA, 18:1n-9) and docosahexaenoic acid (DHA, 22:6n-3) were used as methyl esters. The fatty acid was dissolved in $99 \%$ ethanol and stored as stock solution $(150 \mathrm{mM})$ under nitrogen at $-80^{\circ} \mathrm{C}$. For all experiments, fatty acid was prepared freshly from stock solution and diluted with growth culture medium (final ethanol concentration: $0.02 \%)$.

\section{Cell culture}

The human breast carcinoma cell lines MDA-MB-231 and MCF-7 were obtained from American Type Culture Collection (LGC Promochem, France) and MCF-7dox cell line was a gift of Dr K. Cowan (National Cancer Institute, Bethesda, MD). MCF-7 is as drug sensitive, P-gp negative cell line. The MCF-7dox was originally established by in vitro selection with increasing concentrations of doxorubicin [31]. Cell lines were cultured in Dulbecco's modified Eagle's medium (DMEM) containing 5\% heat-inactivated fetal calf serum, $50 \mathrm{UI} / \mathrm{ml}$ penicillin and $50 \mu \mathrm{g} / \mathrm{ml}$ streptomycin (Cambrex, France). MCF-7dox cells were grown in the 
presence of $1 \mu \mathrm{M}$ doxorubicin to maintain the multidrug-resistant phenotype. Two weeks before experiments were performed, MCF-7dox cells were removed from doxorubicincontaining medium and maintained in doxorubicin-free medium as described previously [31]. Cells were seeded at low density $\left(2 \times 10^{4}\right.$ cells $\left./ \mathrm{cm}^{2}\right)$ and one day after seeding the medium was removed and replaced by the same growth medium containing $0.02 \%$ ethanol (Control) or fatty acid $(30 \mu \mathrm{M})$. The cells were cultured one week before experiments $\left(37^{\circ} \mathrm{C}\right.$ in a humidified incubator with $5 \% \mathrm{CO}_{2}$ ). The culture medium was changed each $24 \mathrm{~h}$.

\section{Fatty acid analysis}

After two rinses with ice-cold PBS, cells cultured in $175-\mathrm{cm}^{2}$ flasks were scraped off with a rubber policeman. They were collected in ice-cold PBS and centrifuged at 1,000 x $\mathrm{g}$ for 5 min. Total lipids were then immediately extracted from the cell pellet according to the method of Bligh and Dyer [32]. Lipid extract was evaporated under vacuum and lipid classes were separated by silica gel thin layer chromatography with hexane/diethyl ether/acetic acid (70/30/1, v/v). Phospholipids spots were scraped and collected in screw-cap glass tubes. Lipids were dissolved in $2 \mathrm{ml} 14 \%$ boron trifluoride in methanol and tubes were closed under nitrogen. Transesterification was obtained by heating at $100^{\circ} \mathrm{C}$ for 90 minutes [33]. Fatty acid methyl esters were extracted with hexane and analyzed by gas chromatography (GC Trace, Thermo-Finnigan, Les Ulis, France). The column was $60 \mathrm{~m}$ long, $0.25 \mathrm{~mm}$ internal diameter with a $0.25 \mu \mathrm{m}$ thickness BPX70 phase (SGE, Courtaboeuf, France). Fatty acids were identified by comparing their retention times with those of authenticated fatty acids. Each fatty acid was quantified by comparing its peak area with that of nonadecanoic acid (internal standard). Results were expressed as mole of fatty acid per 100 moles total fatty acids $($ mole $\%)$. 


\section{Cell cytotoxicity}

Cells were seeded in standard 96-well plates $\left(7 \times 10^{3}\right.$ cells/well). One day after seeding, the culture medium was changed and replaced by medium containing different concentration of doxorubicin $\left(10^{-10}\right.$ to $\left.10^{-4} \mathrm{M}\right)$ with or without DHA $(30 \mu \mathrm{M})$ during 7 days. Viability of cells were measured as a whole by the tetrazolium salt assay [34]. Cells were incubated at $37^{\circ} \mathrm{C}$ for 1 hour with the tetrazolium salt (3-[4,5-dimethylthiazol-2-yl]-2,5diphenyl tetrazolium bromide) and metabolically active cells reduced the dye to purple formazan. Formazan crystals were dissolved with DMSO. Cell viability was expressed as formazan $570 \mathrm{~nm}$ absorbance and for each well, the absorbance value was expressed as the percentage of the absorbance value of control, non treated cells. These values were fitted to sigmoidal dose-response model (GraphPad Prism ${ }^{\circledR}$, GraphPad Software Inc):

$$
\mathrm{Y}=\operatorname{Min}+(\operatorname{Max}-\operatorname{Min}) /\left(1+10_{50}^{\log \mathrm{IC}_{50}}-\mathrm{X}\right)
$$

with :

$$
\begin{aligned}
& \text { Min }=\text { minimum viability } \\
& \text { Max = maximum viability } \\
& \mathrm{X}=\mathrm{Log} \text { (doxorubicin concentration, in } \mathrm{M}) \\
& \mathrm{IC}_{50}=\text { concentration of doxorubicin producing a } 50 \% \text { decrease of viability }
\end{aligned}
$$

Cellular ${ }^{14}$ C-Doxorubicin accumulation

Cells were seeded in standard 6-well plates at $18 \times 10^{4}$ cells/well. One day after seeding, the culture medium was changed and replaced by medium with or without DHA $(30 \mu \mathrm{M})$ during 7 days. The cells were washed twice with $5 \mathrm{ml}$ of Hanks' medium then [14- $\left.{ }^{14} \mathrm{C}\right]$-Doxorubicin hydrochloride $(1.5 \mathrm{ml}$ of $5 \mu \mathrm{M}$ doxorubicin solution) was added. After $3 \mathrm{~h}$ of incubation the doxorubicin solution was discarded then the cells were washed 3 times with $5 \mathrm{ml}$ of ice-cold Hanks' medium. Then $1 \mathrm{ml}$ of $\mathrm{NaOH} 1 \mathrm{~N}$ was added to the cells, and then transferred in stoppered tubes for $1 \mathrm{~h}$ at $60^{\circ} \mathrm{C}$. After keeping an aliquot $(100 \mu \mathrm{l})$ for the 
determination of the protein content according to Lowry et al [35], $700 \mu 1$ were placed in scintillation vials and $3 \mathrm{ml}$ of scintillation liquid (Ultima Gold XR, Packard) were added, then radioactivity was determined in a liquid scintillation counter Tri-Carb 2100 TR (Packard, France).

\section{Measurement of malondialdehyde, GSH and GSSG}

Malondialdehyde was measured by UV-HPLC, according to Steghens et al [36], as a diaminonaphtalene derivative which displays a highly specific spectrum, very different from that of other short chain aldehydes such as formaldehyde or acetaldehyde.

Reduced glutathione (GSH) and disulfide glutathione (GSSG) were measured by a fast new HPLC/MS method recently described [37] with only a modification for the sample preparation: as the protein content (and thus the buffering capacity) of cell extracts is very low in comparison with whole blood, cell extracts $(50 \mu \mathrm{l})$ were first vortex mixed with a solution containing N-ethyl-maleimide, EDTA and $\gamma$-glutamylglutamic acid as an internal standard, incubated $20 \mathrm{~min}$ at room temperature and then deproteinised with sulfosalicilic acid.

Vitamin E analysis

Total lipids were extracted from the cell pellet according to Bligh and Dyer extraction procedure [32]. Delta-tocopherol was added as an internal standard (at $0.625 \mu \mathrm{g} / \mathrm{ml}$ in hexane) to the lipid extract, which was evaporated to dryness under vacuum, then taken up with $2 \mathrm{ml}$ hexane, and washed with $1 \mathrm{ml}$ PBS. Lipids were redissolved in $300 \mu \mathrm{l}$ methanol and $80 \mu \mathrm{l}$ were injected for tocopherols separation and quantification by High Pressure Liquid Chromatography (HPLC) system [38]. Solvent was methanol, which was isocratically pumped at $1 \mathrm{ml}$ per minute through a $250 \times 4.6 \mathrm{~mm}$ reverse phase octadecyl-bonded silica 
column (Waters Spherisorb ODS2, Thermo-Finnigan, Les Ulis, France). Detection of tocopherols was performed with a fluorimeter with excitation wavelength set at $290 \mathrm{~nm}$ and detection at $334 \mathrm{~nm}$, coupled with a SP4270 Integrator (Spectraphysics). Separated compounds were quantified by comparison of their peak areas with that of delta-tocopherol used as an internal standard.

\section{Statistics}

Statistical analysis was carried out using Student's unpaired t-test, one-way ANOVA and Newman-Keuls multiple comparison tests (GraphPad Prism ${ }^{\circledR}$, GraphPad Software Inc); $\mathrm{p}<0.05$ was regarded as significant. 


\section{RESULTS}

\section{Fatty acid composition of membrane phospholipids}

Table 1 shows the composition in mole \% of the membrane phospholipids fatty acids (pooled in series) of MDA-MB-231, MCF-7 and MCF-7dox. In control conditions (ethanol: $0.02 \%$ ), no statistical difference existed between fatty acid composition of these three cell lines (ANOVA, $\mathrm{p}>0.05)$. DHA $(30 \mu \mathrm{M})$ supplementation led to an increased level of total $\mathrm{n}-3$ fatty acids for MDA-MB-231 and MCF-7dox cell lines (Student's t-test, $\mathrm{p}<0.05$ ). This increase involved both 22:6n-3 and 20:5n-3 fatty acids in MDA-MB-231 whereas only 22:6n-3 was statistically increased in MCF-7 and MCF-7dox. Despite the same basal level in MDA-MB-231 and MCF-7 sensitive cell lines membranes, DHA supplementation induced a higher increase of 22:6n-3 incorporation in MDA-MB-231 (by 2.5 -fold, $\mathrm{p}<0.01$ ) than in MCF-7 (by 1.4-fold, p < 0.05). Enrichment ratios of MDA-MB-231 and MCF-7 were statistically different (Newman-Keuls test, $\mathrm{p}<0.05$ ). In MCF-7dox, DHA led to a higher increase in the level of 22:6n-3 (by 1.7-fold, p < 0.05) than parental MCF-7 cell line. However, no statistical difference (Newman-Keuls test, $p>0.05$ ) were observed between the enrichment ratios of MCF-7 and MCF-7dox cell lines.

\section{Doxorubicin cytotoxicity}

Breast cancer cells were cultured during 7 days in a medium supplemented without or with DHA $30 \mu \mathrm{M}$ along with doxorubicin concentrations ranging from $10^{-10} \mathrm{M}$ to $10^{-4} \mathrm{M}$. By using cell survival assay (blue trypan exclusion), we confirmed that the concentration of DHA used $(30 \mu \mathrm{M})$ was not toxic for the three cell lines (data not shown). 
In control conditions, the calculated concentration of doxorubicin inducing $50 \%$ cell mortality $\left(\mathrm{IC}_{50}\right)$ were dependent on the cell line $(11.8 \pm 1.0 \mathrm{nM}$ for MDA-MB-231, $111 \pm 16 \mathrm{nM}$ for MCF-7 and 7.0 $\pm 0.8 \mu \mathrm{M}$ for resistant cell line MCF-7dox). Figure 1 shows the dose-response curves obtained with the three cell lines. In MDA-MB-231, DHA supplementation led to an increase in doxorubicin toxicity at concentrations comprised between $10^{-9}$ and $10^{-7} \mathrm{M}\left(\right.$ Fig. 1A). The $\mathrm{IC}_{50}$ shifted from $11.8 \pm 1.0 \mathrm{nM}$ to $3.8 \pm 0.3 \mathrm{nM}$ when the cells were enriched with DHA. This enhancement of doxorubicin cytotoxicity $(\approx 3$ fold) by DHA was statistically significant ( $\mathrm{p}<0.001)$. In contrast, supplementation of MCF-7 cells during 7 days with DHA (Fig. 1B) did not modify doxorubicin cytotoxicity : $\mathrm{IC}_{50}=93 \pm$ $15 \mathrm{nM}$ versus $111 \pm 16 \mathrm{nM}$ in supplemented versus non supplemented cells, respectively ( $\mathrm{p}$ > 0.05). In the doxorubicin resistant cell line MCF-7dox (Fig. 1C), $\mathrm{IC}_{50}$ significantly shifted from $7.0 \pm 0.8 \mu \mathrm{M}$ to $3.3 \pm 0.5 \mu \mathrm{M}$ when cells were supplemented with DHA $30 \mu \mathrm{M}$ (p < $0.001)$.

\section{Doxorubicin accumulation}

Figure 2B shows the levels of intracellular accumulation of ${ }^{14} \mathrm{C}$-doxorubicin $(5 \mu \mathrm{M})$ after 3-hours incubation in MDA-MB-231, MCF-7 or MCF-7dox cells with or without DHA supplementation, in comparison with the DHA enrichment within cell membranes (Fig. 2A). No relation was found in any cell line between DHA enrichment and the accumulation of doxorubicin inside the cells. The basal level of doxorubicin was similar in MDA-MB-231 and MCF-7 cells and was not modified by DHA supplementation. In control condition $(0.02 \%$ ethanol), accumulation of ${ }^{14} \mathrm{C}$-doxorubicin in MCF-7dox was 3-fold lower than that of the parental MCF-7 cell line (170 \pm 30 versus $546 \pm 70 \mathrm{pmol} / \mathrm{mg}$ proteins, respectively) and remained unchanged after DHA supplementation. Furthermore, measure of P-gp activity by rhodamine 123, a fluorescent substrate, did not show any changes in rhodamine 123 efflux in 
DHA-treated cells (data not shown). Thus, DHA incorporation in cellular membrane did not lead to any changes in doxorubicin accumulation, whatever the breast cancer cell type studied.

\section{Malondialdehyde, glutathione and alpha-tocopherol levels}

We studied lipid peroxidation in cells supplemented or not, with DHA or oleic acid (18:1n-9) a monounsaturated fatty acid. In control conditions, basal levels of malondialdehyde were not statistically different (ANOVA, $p>0.05$ ) : 45 $\pm 15,32 \pm 10$ and $38 \pm 4 \mathrm{nmol} / \mathrm{g}$ proteins in MDA-MB-231, MCF-7 and MCF-7dox cell lines, respectively (Fig. 3) and oleic acid supplementation did not lead to any change in these levels (data not shown). In contrast, DHA supplementation led to a marked ( $\approx 4$-fold) increase of the malondialdehyde in the three cell lines. At $30 \mu \mathrm{M}$ DHA, under conditions where no cytotoxicity was detectable, malondialdehyde reached $165 \mathrm{nmol} / \mathrm{g}$ proteins in MDA-MB-231, a similar level in MCF-7, and $242 \mathrm{nmol} / \mathrm{g}$ proteins in MCF-7dox ( $<$ 0.01). Doxorubicin, used at its $\mathrm{IC}_{50}$ concentration, led to a 3.3-fold malondialdehyde level increase in MDA-MB231. No such change was found in MCF-7 or in MCF-7dox cells.

Co-treatment with doxorubicin and DHA further increased cumulatively malondialdehyde (303 \pm 49 versus $166 \pm 45 \mathrm{nmol} / \mathrm{g}$ proteins, $\mathrm{p}<0.01)$ in MDA-MB-231 compared to DHA alone. In MCF-7 cells, there was also an increase in malondialdehyde, although the extent was much lower $(203 \pm 12$ versus $165 \pm 23 \mathrm{nmol} / \mathrm{g}$ proteins, $\mathrm{p}<0.05)$. In resistant cell line MCF-7dox, despite a 3.7-fold higher level in cells treated both with doxorubicin and DHA, this level remained lower than that induced by DHA supplementation alone.

Figure 3 indicates that basal glutathione was in the same order of level in the three cell line $(\approx 50 \mu \mathrm{mol} / \mathrm{g}$ proteins $)$ and was increased by DHA $(2.2$-fold, $\mathrm{p}<0.05)$ only in 
MDA-MB-231. GSH level was slightly increased (by 1.3- and 1.8-fold) in doxorubicintreated MDA-MB-231 and MCF-7 cells compared to control conditions. By contrast, doxorubicin led to a weak GSH level decrease in MCF-7dox. During co-treatment with DHA plus doxorubicin, a higher increase of GSH level was observed only in MDA-MB-231 compared to control conditions (167 \pm 39 versus $53 \pm 7, \mathrm{p}<0.05)$.

Glutathione disulfide (GSSG) was also measured. Its level is very low or undetectable. When GSSG level was measurable, GSSG level was increased by DHA in MDA-MB-231 by 1.5-fold compared to control cells $(2.4 \pm 0.2$ versus $1.6 \pm 0.2 \mu \mathrm{mol} / \mathrm{g}$ proteins, $\mathrm{p}<0.001)$. Its level was unchanged with DHA in MCF-7 compared to control conditions $(0.7 \pm 0.4$ versus $0.5 \pm 0.4 \mu \mathrm{mol} / \mathrm{g}$ proteins). GSSG level was undetectable in DHA-treated MCF-7-dox compared to control $(0.3 \pm 0.1 \mu \mathrm{mol} / \mathrm{g}$ proteins $)$.

Finally, alpha-tocopherol, measured in each of the three cell lines, was found to be undetectable ( $<5 \mathrm{ng}$ per $10^{8}$ cells) whatever the condition explored: ethanol, DHA $(30 \mu \mathrm{M})$, doxorubicin ( $\mathrm{IC}_{50}$ concentration for each cell line) or doxorubicin plus DHA, $(\mathrm{n}=6$ for each condition). Alpha-tocopherol was also undetectable in the culture medium although trace of gamma-tocopherol was found. 


\section{DISCUSSION}

Our study demonstrates that sensitivity of breast cancer cells to doxorubicin can be increased when an oxidative stress is triggered, a condition brought about by a supplementation with DHA. We have taken advantage of the differential sensitivity of three breast cancer cell lines to doxorubicin and DHA in order to investigate mechanisms responsible for the chemosensitization induced by DHA. We found it to be cell-line selective, affecting MDA-MB-231 and resistant MCF-7dox cells but not the parental cell line MCF-7. MCF-7 is the cell line with the lower incorporation of DHA in phospholipids after 7 days supplementation. However, when the DHA supplementation was applied during 10 days in MCF-7, the greatest DHA enrichment obtained did not lead to any change in doxorubicin sensitivity (data not shown), thus showing the lack of relation between drug toxicity and the level of membrane DHA. In MDA-MB-231, sensitization to doxorubicin by DHA was associated with an increase in malondialdehyde and in GSH levels, indicating that an oxidative stress took place. In MCF-7 cells, the slight increase in malondialdehyde observed, although indicative of lipid peroxidation, was not sufficient to trigger a noteworthy oxidative stress since there was no change in GSH. This suggests the need for a threshold in lipoperoxidation products for amplification of doxorubicin cytotoxic action to occur. Alternately, the fact that EPA was increased substantially in MDA-MB-231 compared to MCF-7 subsequent to DHA treatment indicates that this fatty acid may also plays a role in the phenomenon. The absence of alpha-tocopherol in all cell lines rules out the hypothesis that lipid antioxidants influenced our results [39].

We considered the possibility that DHA might alter the pharmacokinetics parameters of doxorubicin, since DHA may cause greater membrane permeability, thus increasing doxorubicin accumulation [14, 40, 41]. In our study, doxorubicin accumulation was similar in 
the two drug-sensitive cell lines MDA-MB-231 and MCF-7 in basal conditions. It was 3-fold lower in MCF-7dox, which are resistant cells with a membrane glycoprotein (P-gp) that functions as an efflux pump for cytotoxic drugs, accounting for the low doxorubicin accumulation. After DHA supplementation, the greater incorporation of DHA into MDA-MB-231 cell membranes (2.5-fold) compared to MCF-7 (1.4-fold), contrasted sharply with the similar accumulation level of doxorubicin between MDA-MB-231 and MCF-7. This indicates that the steady state level of doxorubicin is not influenced by membrane lipid composition in these two sensitive cell lines. Despite the modification in DHA level of MCF-7dox membrane phospholipids (1.7-fold), DHA supplementation did not change apparently drug diffusion or P-gp drug efflux. Since DHA enhanced sensitivity of MDA-MB-231 and MCF-7dox to doxorubicin, then chemosensitization induced by DHA cannot be correlated to anti-cancer drug intracellular concentration.

Reactive oxygen species (ROS), which are continuously produced in cells can stimulate lipid peroxidation and contribute for example to cell multiplication or differentiation through generation of biologically active lipid peroxidation products such as malondialdehyde and 4-hydroxyalkenals, which are physiologically present in cells at low concentration [42, 43]. The level of malondialdehyde was significantly higher after DHA supplementation than in control conditions in the three cell line studied. The increased malondialdehyde level observed in sensitive cells treated with DHA alone (166 and $165 \mathrm{nmol} / \mathrm{g}$ proteins in MDA-MB-231 and MCF-7 cells, respectively) or in MCF-7dox resistant cells (242 nmol/g proteins) may not be sufficient to alter cell viability, although it might be sufficient to slightly decrease cell proliferation, as observed during DHA supplementation (data not shown).

Several mechanisms have been proposed to explain doxorubicin cytotoxic action. These include intercalation into DNA, initiation of DNA damage via the inhibition of topoisomerase II. Doxorubicin is also an anti-cancer drug known for its ability to generate 
ROS and to increase lipid peroxidation [21]. Lipid peroxidation is commonly regarded as a deleterious mechanism, leading to structural modification of complex lipid protein assemblies, such as biomembranes, and is usually associated with cellular dysfunction [20, $44,45]$. In our study, lipid peroxidation induced by doxorubicin treatment was cell-line selective since this drug led to a 3-fold increase in malondialdehyde level in MDA-MB-231 but not in MCF-7 cells. So, lipoperoxidation could damage MDA-MB-231 cells and strengthen the effect of other mechanisms involved in doxorubicin cytotoxicity. This observation might explain why doxorubicin toxicity, in control conditions, was greater in MDA-MB-231 than in MCF-7, with an $\mathrm{IC}_{50}$ at $11.8 \mathrm{nM}$ and $111 \mathrm{nM}$, respectively. In the present study, we observed that the enhancement of the sensitivity to doxorubicin by DHA affects MDA-MB-231 but not MCF-7 cell line. Since MDA-MB-231 was the only chemosensitive cell line where malondialdehyde level increased with either DHA or doxorubicin treatment, the cumulative increase of malondialdehyde level observed with cotreatment might be sufficient to trigger a noteworthy oxidative stress for amplification of doxorubicin cytotoxicity. By contrast, in MCF-7 cells, the slight increase in malondialdehyde observed with co-treatment, although indicative of lipid peroxidation, might not have been sufficient for cytotoxic substances to reach the threshold required for cytotoxicity. Existence of a cytotoxic threshold has already been described by others using 4-hydroxynonenal as a marker of lipid peroxidation [42].

Furthermore, the increase in glutathione level induced by either treatment occurred only in MDA-MB-231. Similar to GSH, GSSG level increased after DHA supplementation in MDA-MB-231 but not in MCF-7 cells. GSH plays a major role in detoxification of a variety of electrophilic compounds and peroxides via catalysis by antioxidant enzymes such as glutathione peroxidase and glutathione S-transferase [46], resulting in formation of its oxidized form, disulfide glutathione (GSSG). It has been reported that initial depletion of 
GSH subsequent to its consumption by antioxidant enzymes during the first hours of oxidant exposure is followed by an increased activity of $\gamma$-glutamyl-cysteine synthetase, the key enzyme of GSH synthesis [47-50]. It should be stressed that in this study the level of GSH was measured 7 days after DHA exposure, and therefore represents steady-state level and not acute response to a primary oxidative stress. Both increased level of GSH and GSSG in MDA-MB-231 suggests that an oxidative stress has been operating for several days. Elevated intracellular GSH providing a reducing environment could indicate adaptation of cells against an oxidative stress, potentially contributing to drug resistance [51, 52]. However, in MDA-MB-231, the hypothesis that increased GSH protects cells against doxorubicin-induced oxidative stress is not supported by the increased chemosensitivity found after DHA treatment. So, alternatively to an activation of enzyme in GSH biosynthesis, increased glutathione could be also the consequence of its lower utilization in relation to an inhibition of consuming enzyme such as glutathione peroxidase or glutathione S-transferase. Such an hypothesis has already been explored by others, who reported that DHA decrease glutathione peroxidase in endothelial cells [26].

Despite the lack of an oxidative stress the reasons why DHA chemosensitizes MCF-7dox to doxorubicin are not clear. The resistance is associated with gene amplification such as, for example, increased expression of antioxidant enzymes, increased expression of the drug transporter P-glycoprotein, elevated cytosolic $\mathrm{pH}[30,53]$. We may therefore contemplate the possibility that DHA modified one of these resistance pathways, leading in turn to enhanced sensitivity of these cells to doxorubicin. Additional studies on antioxidant enzyme regulation by DHA in three cell types should allow a better understanding of differential sensitivity to doxorubicin and DHA.

In conclusion, we suggest that the differential effect of DHA on the sensitivity of the two different cell lines MDA-MB-231 and MCF-7 to doxorubicin results from their 
differential oxidative response to doxorubicin, but not to DHA. MDA-MB-231 seems to be the only cell line where a cumulative effect of DHA and doxorubicin could lead to a level of lipid peroxidation sufficient enough to induce cell death. In MCF-7, doxorubicin did not lead to such an oxidative stress. Consequently, although DHA was equally peroxidized in the two cell lines, this effect was not sufficient to induce an increased cytotoxicity in MCF-7. Therefore, the pro-oxidant abilities of anticancer agents such as anthracyclines should not be underestimated. This process appears as a promising way to increase their efficacy in presence of physiological molecules such as omega-3 polyunsaturated fatty acids.

Abbreviations used:

DHA: docosahexaenoic acid ; GSH: glutathione (reduced); GSSG: glutathione (oxidized) ; MDR: multidrug resistance ; P-gp: P-glycoprotein ; PUFA: polyunsaturated fatty acid ; ROS : reactive oxygen species 


\section{REFERENCES}

[1] Bougnoux, P.; Maillard, V.; Ferrari, P.; Jourdan, M. L.; Chajes, V. n-3 fatty acids and breast cancer. IARC Sci. Publ. 156:337-341; 2002.

[2] Franceschi, S.; Favero, A.; Decarli, A.; Negri, E.; La Vecchia, C.; Ferraroni, M.; Russo, A.; Salvini, S.; Amadori, D.; Conti, E.; et al. Intake of macronutrients and risk of breast cancer. Lancet. 347:1351-1356; 1996.

[3] Rose, D. P.; Connolly, J. M. Omega-3 fatty acids as cancer chemopreventive agents. Pharmacol. Ther. 83:217-244; 1999.

[4] Maillard, V.; Bougnoux, P.; Ferrari, P.; Jourdan, M. L.; Pinault, M.; Lavillonniere, F.; Body, G.; Le Floch, O.; Chajes, V. N-3 and N-6 fatty acids in breast adipose tissue and relative risk of breast cancer in a case-control study in Tours, France. Int. J. Cancer. 98:78-83; 2002.

[5] Bagga, D.; Anders, K. H.; Wang, H. J.; Glaspy, J. A. Long-chain n-3-to-n-6 polyunsaturated fatty acid ratios in breast adipose tissue from women with and without breast cancer. Nutr. Cancer. 42:180-185; 2002.

[6] Goodstine, S. L.; Zheng, T.; Holford, T. R.; Ward, B. A.; Carter, D.; Owens, P. H.; Mayne, S. T. Dietary (n-3)/(n-6) fatty acid ratio: possible relationship to premenopausal but not postmenopausal breast cancer risk in U.S. women. J. Nutr. 133:1409-1414; 2003.

[7] Hardman, W. E.; Avula, C. P.; Fernandes, G.; Cameron, I. L. Three percent dietary fish oil concentrate increased efficacy of doxorubicin against MDA-MB 231 breast cancer xenografts. Clin. Cancer Res. 7:2041-2049; 2001.

[8] Das, U. N. Essential fatty acids and their metabolites and cancer. Nutrition. 15:239-240; 1999. 
[9] Germain, E.; Chajes, V.; Cognault, S.; Lhuillery, C.; Bougnoux, P. Enhancement of doxorubicin cytotoxicity by polyunsaturated fatty acids in the human breast tumor cell line MDA-MB-231: relationship to lipid peroxidation. Int. J. Cancer. 75:578-583; 1998.

[10] Hardman, W. E. Omega-3 fatty acids to augment cancer therapy. J. Nutr. 132:3508S$3512 S ; 2002$.

[11] Jump, D. B. Fatty acid regulation of gene transcription. Crit. Rev. Clin. Lab. Sci. 41:41$78 ; 2004$.

[12] Narayanan, B. A.; Narayanan, N. K.; Reddy, B. S. Docosahexaenoic acid regulated genes and transcription factors inducing apoptosis in human colon cancer cells. Int. J. Oncol. 19:1255-1262; 2001.

[13] Chamras, H.; Ardashian, A.; Heber, D.; Glaspy, J. A. Fatty acid modulation of MCF-7 human breast cancer cell proliferation, apoptosis and differentiation. J. Nutr. Biochem. $13: 711-716 ; 2002$.

[14] Burns, C. P.; North, J. A. Adriamycin transport and sensitivity in fatty acid-modified leukemia cells. Biochim. Biophys. Acta. 888:10-17; 1986.

[15] Spector, A. A.; Burns, C. P. Biological and therapeutic potential of membrane lipid modification in tumors. Cancer Res. 47:4529-4537; 1987.

[16] Das, U. N. Essential fatty acids, lipid peroxidation and apoptosis. Prostaglandins Leukot. Essent. Fatty Acids. 61:157-163; 1999.

[17] Stoll, B. A. N-3 fatty acids and lipid peroxidation in breast cancer inhibition. Br. J. Nutr. 87:193-198; 2002.

[18] Menendez, J. A.; Mehmi, I.; Atlas, E.; Colomer, R.; Lupu, R. Novel signaling molecules implicated in tumor-associated fatty acid synthase-dependent breast cancer cell proliferation and survival: Role of exogenous dietary fatty acids, p53-p21WAF1/CIP1, ERK1/2 MAPK, p27KIP1, BRCA1, and NF-kappaB. Int. J. Oncol. 24:591-608; 2004. 
[19] Das, U. A radical approach to cancer. Med. Sci. Monit. 8:RA79-92; 2002.

[20] Spiteller, G. Are lipid peroxidation processes induced by changes in the cell wall structure and how are these processes connected with diseases? Med. Hypotheses. 60:69$83 ; 2003$.

[21] Sinha, B. K.; Mimnaugh, E. G.; Rajagopalan, S.; Myers, C. E. Adriamycin activation and oxygen free radical formation in human breast tumor cells: protective role of glutathione peroxidase in adriamycin resistance. Cancer Res. 49:3844-3848; 1989.

[22] Quiles, J. L.; Huertas, J. R.; Battino, M.; Mataix, J.; Ramirez-Tortosa, M. C. Antioxidant nutrients and adriamycin toxicity. Toxicology. 180:79-95; 2002.

[23] Palozza, P.; Sgarlata, E.; Luberto, C.; Piccioni, E.; Anti, M.; Marra, G.; Armelao, F.; Franceschelli, P.; Bartoli, G. M. n-3 fatty acids induce oxidative modifications in human erythrocytes depending on dose and duration of dietary supplementation. Am. J. Clin. Nutr. 64:297-304; 1996.

[24] Kubo, K.; Saito, M.; Tadokoro, T.; Maekawa, A. Changes in susceptibility of tissues to lipid peroxidation after ingestion of various levels of docosahexaenoic acid and vitamin $\mathrm{E}$. Br. J. Nutr. 78:655-669; 1997.

[25] Jenkinson, A.; Franklin, M. F.; Wahle, K.; Duthie, G. G. Dietary intakes of polyunsaturated fatty acids and indices of oxidative stress in human volunteers. Eur. J. Clin. Nutr. 53:523-528; 1999.

[26] Delton-Vandenbroucke, I.; Vericel, E.; Januel, C.; Carreras, M.; Lecomte, M.; Lagarde, M. Dual regulation of glutathione peroxidase by docosahexaenoic acid in endothelial cells depending on concentration and vascular bed origin. Free Radic. Biol. Med. 30:895-904; 2001. 
[27] Lemaitre, D.; Vericel, E.; Polette, A.; Lagarde, M. Effects of fatty acids on human platelet glutathione peroxidase: possible role of oxidative stress. Biochem. Pharmacol. 53:479-486; 1997.

[28] Polavarapu, R.; Spitz, D. R.; Sim, J. E.; Follansbee, M. H.; Oberley, L. W.; Rahemtulla, A.; Nanji, A. A. Increased lipid peroxidation and impaired antioxidant enzyme function is associated with pathological liver injury in experimental alcoholic liver disease in rats fed diets high in corn oil and fish oil. Hepatology. 27:1317-1323; 1998.

[29] Krishna, R.; Mayer, L. D. Multidrug resistance (MDR) in cancer. Mechanisms, reversal using modulators of MDR and the role of MDR modulators in influencing the pharmacokinetics of anticancer drugs. Eur. J. Pharm. Sci. 11:265-283; 2000.

[30] Sinha, B. K.; Mimnaugh, E. G. Free radicals and anticancer drug resistance: oxygen free radicals in the mechanisms of drug cytotoxicity and resistance by certain tumors. Free Radic. Biol. Med. 8:567-581; 1990.

[31] Fairchild, C. R.; Ivy, S. P.; Kao-Shan, C. S.; Whang-Peng, J.; Rosen, N.; Israel, M. A.; Melera, P. W.; Cowan, K. H.; Goldsmith, M. E. Isolation of amplified and overexpressed DNA sequences from adriamycin-resistant human breast cancer cells. Cancer Res. 47:5141-5148; 1987.

[32] Bligh, E. G.; Dyer, W. J. A rapid method of total lipid extraction and purification. Can. J. Med. Sci. 37:911-917; 1959.

[33] Morrison, W. R.; Smith, L. M. Preparation of fatty acid methyl esters and dimethylacetals from lipids with boron fluoride-methanol. J. Lipid Res. 53:600-608; 1964.

[34] Mosmann, T. Rapid colorimetric assay for cellular growth and survival: application to proliferation and cytotoxicity assays. J. Immunol. Methods. 65:55-63; 1983.

[35] Lowry, O. H.; Rosebrough, N. J.; Farr, A. L.; Randall, R. J. Protein measurement with the Folin phenol reagent. J. Biol. Chem. 193:265-275; 1951. 
[36] Steghens, J. P.; van Kappel, A. L.; Denis, I.; Collombel, C. Diaminonaphtalene, a new highly specific reagent for HPLC-UV measurement of total and free malondialdehyde in human plasma or serum. Free Radic. Biol. Med. 31:242-249; 2001.

[37] Steghens, J. P.; Flourie, F.; Arab, K.; Collombel, C. Fast liquid chromatography-mass spectrometry glutathione measurement in whole blood: micromolar GSSG is a sample preparation artifact. J. Chromatogr. B Analyt. Technol. Biomed. Life Sci. 798:343-349; 2003.

[38] Hatam, L. J.; Kayden, H. J. A high-performance liquid chromatographic method for the determination of tocopherol in plasma and cellular elements of the blood. J. Lipid Res. 20:639-645; 1979.

[39] Kim, H. Y.; Akbar, M.; Lau, A.; Edsall, L. Inhibition of neuronal apoptosis by docosahexaenoic acid (22:6n-3). Role of phosphatidylserine in antiapoptotic effect. $J$. Biol. Chem. 275:35215-35223; 2000.

[40] Abulrob, A. N.; Mason, M.; Bryce, R.; Gumbleton, M. The effect of fatty acids and analogues upon intracellular levels of doxorubicin in cells displaying P-glycoprotein mediated multidrug resistance. J. Drug Target. 8:247-256; 2000.

[41] Zijlstra, J. G.; de Vries, E. G.; Muskiet, F. A.; Martini, I. A.; Timmer-Bosscha, H.; Mulder, N. H. Influence of docosahexaenoic acid in vitro on intracellular adriamycin concentration in lymphocytes and human adriamycin-sensitive and -resistant small-cell lung cancer cell lines, and on cytotoxicity in the tumor cell lines. Int. J. Cancer. 40:850$856 ; 1987$.

[42] Dianzani, M. U. 4-hydroxynonenal from pathology to physiology. Mol. Aspects Med. 24:263-272; 2003.

[43] Forman, H. J.; Dickinson, D. A. Introduction to serial reviews on 4-hydroxy-2-nonenal as a signaling molecule. Free Radic. Biol. Med. 37:594-596; 2004. 
[44] Esterbauer, H.; Schaur, R. J.; Zollner, H. Chemistry and biochemistry of 4hydroxynonenal, malonaldehyde and related aldehydes. Free Radic. Biol. Med. 11:81$128 ; 1991$.

[45] Marnett, L. J. Lipid peroxidation-DNA damage by malondialdehyde. Mutat. Res. 424:83$95 ; 1999$.

[46] Griffith, O. W. Biologic and pharmacologic regulation of mammalian glutathione synthesis. Free Radic. Biol. Med. 27:922-935; 1999.

[47] Shi, M. M.; Kugelman, A.; Iwamoto, T.; Tian, L.; Forman, H. J. Quinone-induced oxidative stress elevates glutathione and induces gamma-glutamylcysteine synthetase activity in rat lung epithelial L2 cells. J. Biol. Chem. 269:26512-26517; 1994.

[48] Rahman, I.; Bel, A.; Mulier, B.; Donaldson, K.; MacNee, W. Differential regulation of glutathione by oxidants and dexamethasone in alveolar epithelial cells. Am. J. Physiol. 275:L80-86; 1998.

[49] Dickinson, D. A.; Iles, K. E.; Watanabe, N.; Iwamoto, T.; Zhang, H.; Krzywanski, D. M.; Forman, H. J. 4-hydroxynonenal induces glutamate cysteine ligase through JNK in HBE1 cells. Free Radic. Biol. Med. 33:974-987; 2002.

[50] Tian, L.; Shi, M. M.; Forman, H. J. Increased transcription of the regulatory subunit of gamma-glutamylcysteine synthetase in rat lung epithelial L2 cells exposed to oxidative stress or glutathione depletion. Arch. Biochem. Biophys. 342:126-133; 1997.

[51] Seo, Y. J.; Lee, J. W.; Lee, E. H.; Lee, H. K.; Kim, H. W.; Kim, Y. H. Role of glutathione in the adaptive tolerance to H2O2. Free Radic. Biol. Med. 37:1272-1281; 2004.

[52] O'Brien, M. L.; Tew, K. D. Glutathione and related enzymes in multidrug resistance. Eur. J. Cancer. 32A:967-978; 1996. 
[53] Simon, S.; Roy, D.; Schindler, M. Intracellular $\mathrm{pH}$ and the control of multidrug resistance. Proc. Natl. Acad. Sci. U S A. 91:1128-1132; 1994. 